\title{
Chikungunya infection: six years after, rheumatic morbidity and impaired quality of life persist!
}

\author{
F Simon $^{1 *}$, J Ferraro ${ }^{1}$, E Javelle$^{1}$, C Marimoutou $^{2}$ \\ From International Symposium HIV and Emerging Infectious Diseases 2014 \\ Marseille, France. 21-23 May 2013
}

\section{Background and objective}

In 2006, all the military policemen deployed in Reunion Island during the chikungunya outbreak were enquired, $25 \%$ self-declared chikungunya infection $(\mathrm{CHIK}+)$ and $19 \%$ had positive serology. In 2008, a self-questionnaire was sent to the same persons, 403 responded, 101 were CHIK + . The latter presented higher frequency of rheumatic disorders and significantly lower quality of life (QoL) than non-infected (CHIK-) responders, 30 months after the outbreak. The purpose of this study is to understand if the difference persisted at six years.

\section{Method}

The 646 participants to the 2006 enquiry were sent selfquestionnaires by postmail with informed consent to the present study and proposal of new biological testing. Only 609 could be reached, and 252 fulfilled the questionnaire: $81 \mathrm{CHIK}+(32 \%)$ and 171 CHIK-. The results are based on their declaration. QoL was estimated with the SF-36 scale.

\section{Conclusion}

Despite a possible selection bias of the most symptomatic $\mathrm{CHIK}+$ patients increasing the observed differences, the large differences observed in rheumatic morbidity, fatigue, and QoL lead to the conclusion that CHIK infection has very long term impact on health, social life and QoL with a very low proportion of patients returning to their previous health status.

\section{Authors' details}

${ }^{1}$ Laveran Military Teaching Hospital, French Military Health Service, Marseille, France. ${ }^{2}$ Army Center for Epidemiology and Public Health, Marseille, France.

Published: 23 May 2014

doi:10.1186/1471-2334-14-S2-O21

Cite this article as: Simon et al:: Chikungunya infection: six years after, rheumatic morbidity and impaired quality of life persist!. BMC Infectious Diseases 2014 14(Suppl 2):O21.

\section{Results}

$\mathrm{CHIK}+$ patients declared higher health care consumption between 2008 and 2012 (more frequent general practitioners consultation and use of paracetamol). They complained of more frequent and intense joint pain $(40 \%$ versus $22 \%$ at least once a week, $64 \%$ versus $38 \%$ moderate to intense pain), stiffness and swelling during the same period. They also report more frequent fatigue, headache and depress mood (respectively $60 \%$ versus $32 \%, 42 \%$ vs $29 \%$ and 21 vs $6 \%, p<0.001$ ). Finally all dimension of SF36-QoL were significantly impaired in CHIK+ patients, reflecting social, physical and mental impact of the disease.

'Laveran Military Teaching Hospital, French Military Health Service, Marseille, France

Full list of author information is available at the end of the article

Submit your next manuscript to BioMed Central and take full advantage of:

- Convenient online submission

- Thorough peer review

- No space constraints or color figure charges

- Immediate publication on acceptance

- Inclusion in PubMed, CAS, Scopus and Google Scholar

- Research which is freely available for redistribution
() Biomed Central 